\title{
Instant Searching System for Housing and Food in a City
}

\author{
Prof. Kalyani Pendke ${ }^{2}$, Nishad Wankhede ${ }^{1}$, Mayur Dhole ${ }^{1}$ \\ ${ }^{1}$ BE Student, Computer Science and Engineering Department, Rajiv Gandhi College of Engineering \& Research, \\ Nagpur, Maharashtra, India \\ 2 Assistant Professor, Computer Science and Engineering Department, Rajiv Gandhi College of Engineering \& \\ Research, Nagpur, Maharashtra, India
}

Article Info

Volume 8, Issue 3

Page Number: 178-182

Publication Issue :

May-June-2021

Article History

Accepted : 05 May 2021

Published: 20 May 2021

\section{ABSTRACT}

The current scenario gives rise to a necessity of a single platform of accommodation facilities. It is very difficult to access all accommodation facilities individually. This website can act as an interface between the owners and the users. In this project, we are going to develop an online website which aims at providing accommodation facilities for people. The facilities available are hostels, mess and rooms/flats. Any person can view the details of the facilities but will not be able to give feedback like comments or ratings unless he is a registered user thus disallowing false defamation of any facility. He/She can contact the owner directly with the contact details. To avoid defamatory publicity, only the registered users can add comments.

Keywords :- Intermediate, defamation

\section{INTRODUCTION}

It has been a trend for the last few years for Students to shift from their home city to the cities having an educational hub, incubation centers, Market Cities for higher education, Or Job Application. Shifting from one place to another in a new city or town makes it difficult at the beginning if there is no resident place in the destination. The Main issue after Entering into a new city/town is accommodation. People having a lack of contacts in the city have to roam searching for Rooms, Flats, PG, Hostels for Shelters and Messes, Hotels, etc. in the city. Though they select a place to live, they hardly have any idea about the surrounding of that place.

Business and financial transactions can now be done easily and securely with websites and applications anywhere and anytime. This is a website for people who move to a new city and are proposed with the daunting task of finding shelter and food for their daily life. Upon registering, the user can view hostels, mess, and rooms/flats according to his desired area. The admin will be able to edit, add or remove any advertisement he posts on this website.

\section{LITERATURE SURVEY}

Mobile Application for Guiding Tourist Activities: Tourist Assistant - TAIS: This paper presents a category classification of mobile travel applications accessible at the moment for tourists in application stores for the most popular mobile operation systems (Android and iOS).

Smart Travel Guide: Application for Android Mobile: The challenge address by mobile was the ability to get 
the exact location from the specified favorites, current location, map, the distance between two cities, weather report, find the video to help the user who is new to the city at the traveling time and gets the current location, map, distance between two cities, weather report.

Restaurant Locator and Booking - Yummy! the maker has presented a study on Restaurant Locator and booking services and directed on locating and tracking of android devices. A fine dining restaurant chain, operating from multiple locations in various cities, wanted its customers to locate the nearest restaurant quickly and also see the current waiting time in those restaurants. As an option, a customer could also book a table from the phone only. Therefore, they planned to develop a restaurant locator and booking application, "Yummy!". Yummy! will display the nearest restaurant locations on a map on the basis of the user's current location.

Digital Table Booking and Food Ordering System Using Android Application research work aims to design and implement a remote food ordering system, through which one can order food before visiting a restaurant, book table, and also make payment. Moreover, two or more customers can place orders for the same table from remote locations. This application consists of three applications within itself. First is for the customer who can book tables and place orders. Second is for the kitchen unit in a restaurant, which enables the staff to view current orders. Third is for the manager of that restaurant in order to keep track of all the transactions. The maker has made use of a recommendation engine that suggests menu to a customer while placing order. They have also made use of a compression algorithm that compresses the size of images used throughout the application at various stages. This system increases quality and speed of service. It also increases the popularity of restaurants among potential customers. Implementing this system gives a cost-efficient opportunity to give customers a personalized service experience where they are in control of choosing what they want, when they want it - from dining to ordering to payment.

\section{EXISTING SYSTEM}

The existing system deals with the provision of hostels, mess, and other facilities but to access these we need to download the different app for different purposes. There exist many apps and websites for finding hostels, rented flats/rooms and mess differently, but there isn't any website which combines all these features and projects the necessities of a normal new person in the city, aimed to provide quality facilities at cheap and effective way.

The existing system is flawed as it is a time-consuming process of visiting different websites for individual purposes. Even if there are websites that combine all these facilities it isn't friendly and usually needs the searcher to first create an account before even searching and usually do not show the location on a map. The websites which advertise hostels, flats/rooms, and mess act as middlemen to extort money from innocent customers.

\section{PROPOSED SYSTEM}

In the current scenario when someone shifts to a new city, they go door to door in search of room/flats, hostels, and mess. This is a time-consuming process where there is no surety of the desired outcome. Many websites are developed which provide individual facilities or sometimes in a group and do not cater to the small organizations which provide room/flats, hostels and mess. To overcome this, we are trying to build a website which will provide all facilities of room/flats, hostels and mess on a single platform, thus saving valuable time. As posting an ad here involves directly calling the admin, very smallscale organizations which cannot make use of technology will also be benefitted.

Purpose of this website: The main aim of our project is to create a collective platform of hostels, mess, and rooms/flats which will help new residents to settle in a city without any hassle. This website will allow the user to register with a simple registration module and 
make use of the amenities like a hostel, mess, and rooms/flats. By using this website, the user will save his time and energy as well as money.

We aim to facilitate the user to get the location and details of the hostel/mess/Room in their selected area through this website and place the required facility in order of best to worst by its rating and cost. We are providing facilities to view the path to the Hostel/ Mess/Rooms through the map. We are designed to give Hostel/Mess/Rooms detailed information to the user and to provide security of facilities by allowing admin to post only surveyed reviews.

\section{IMPLEMENTATION}

There are six modules-Registration and login module, user module, admin module, hostel module, rooms or flat module, and mess availability module:

A. Registration and login module: The website will open on the registration and log-in page. Here, the admin can access his account and the users can either create their account or log in to their accounts.

B. User: In this project, we have given a facility to the user to find a nearby mess, hostels, or rooms/flats available in their selected area. Location-based service is another key functionality that gets used in smartphone applications. It is often combined with maps to give a good experience to the user about their location. Here, the user will select his preferred location and he will be given an optimum list of his chosen facility.

C. Admin: Admin can edit, add and remove facilities about Mess, Hostel, and Room/flats. For the prevention of false and defaming comments on any facility, only registered users will be able to comment and rate. Admin will be able to update the information regarding the facilities with only his account.
D. Hostel Module: This module showcases the hostels in different vicinities. Hostels will be given a rating by existing users of that hostel which will be crucial to new users. Hostels will be rated based on the services received by the existing residents.

E. Rooms/ Flats module: This module showcases the rooms and flats available for rent for our users. These can be rated too by existing users. The details of the room/flat like area, amenities, etc will be provided too.

F. Mess module: This module provides information about the mess in different areas. The mess will be rated by existing users which will be of help to the new users registering with this app. Details like cost, menu, etc will be provided as given by the ad owner.

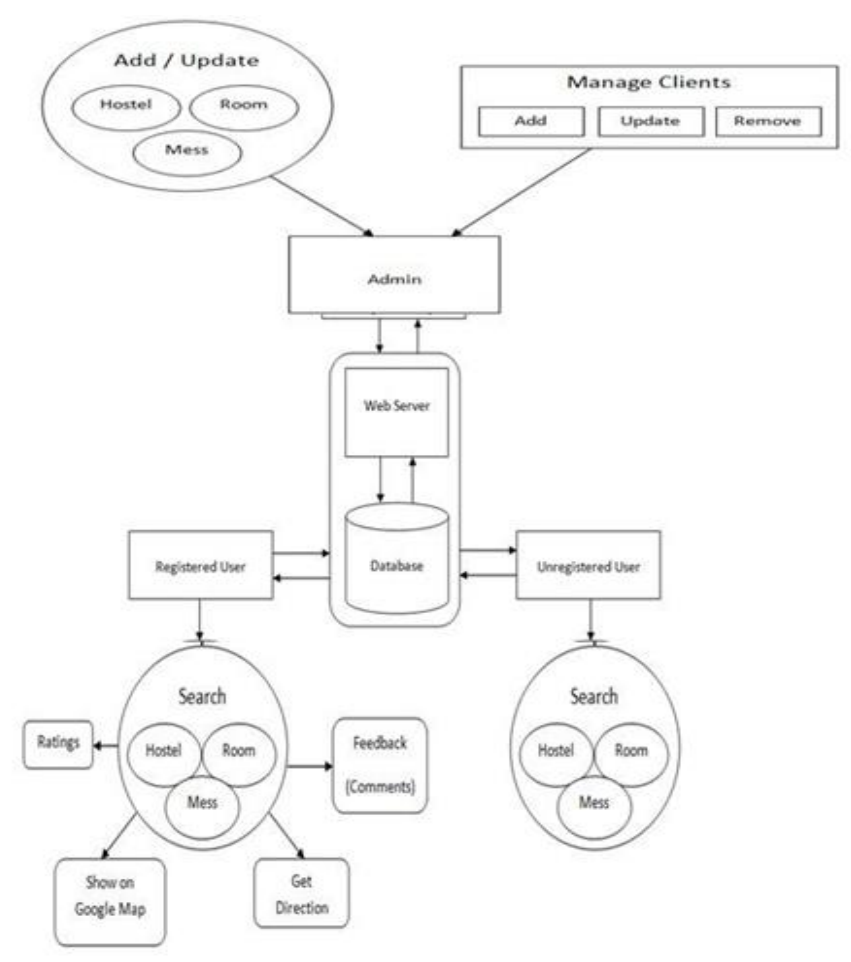

Fig 1 : Block Diagram

\section{RESULT \& DISCUSSION}

We worked with CSS, which helped in designing the site and some picture movement features which helped in giving effective look to the pictures and photographs on the website. We also used Google 
APIs to help the users find their location and the location of the facility they want to use. By giving the location of users, they can track the path needed to get to the respective facility.

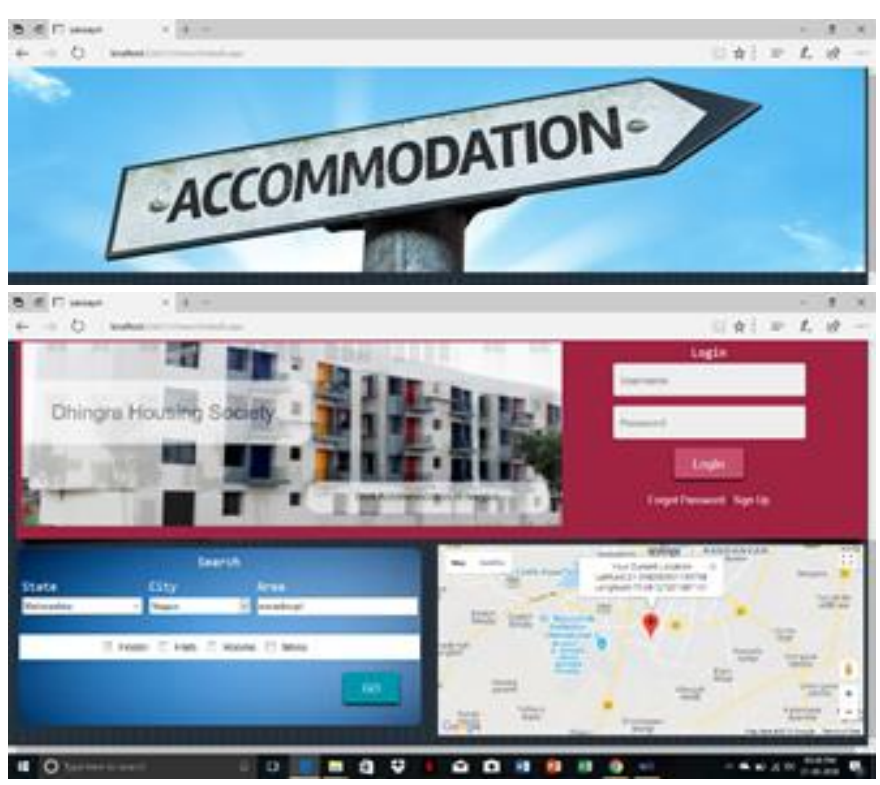

Fig 2 : Home Page

Originally we were planning to make a mobile app for the same purpose, but after researching on the topic and the resources available on this topic it as found that making desktop software or website will be more helpful for users and after the website is made, it can also be converted into a mobile app.

We used asp.net as a platform to create the site instead of using HTML to broaden our scope of computer languages and could code on it to build a website, which helped us a lot in learning a new language.

\section{CONCLUSION}

The problems of new students or people for searching hostel/mess/room can be solved up to large extend. The Location-Based room and mess facilities aim to provide information, to new students and people shifting to new cities for jobs, to reduce their effort and mental stress when people are coming from various regions of India for settling in new cities.

\section{REFERENCES}

[1]. Alexander Smirnov, Alexey Kashevnik, Nikolay Shilov, Nikolay Teslya, Anton Shabaev "Mobile Application for Guiding Tourist Activities: Tourist Assistant - TAIS”, 26 May 2016.

[2]. Archita Diwan1, Madhuri Gawade2, Priyanka Patil3, Shubhangi Thigle "Restaurant Locator and Booking - Yummy!", 2016.

[3]. Dada Jinendra R, Jadhav Bhagyashri R, Gaidhani Pranav Y., Vyavahare Seema U, Achaliya Parag N. "Smart Travel Guide: Application for Android Mobile”, March 2012.

[4]. Prof V. B. Dhore, Surabhi Thakar1, Prajakta Kulkarni2, Rasika Thorat3 "Digital Table Booking and Food Ordering System Using Android Application", International Journal of Emerging Engineering Research and Technology Volume 2, Issue 7, October 2014.

[5]. Overflow http://Creating and Using Databases in Android Part 01 -android10(2002) The IEEE website. [Online]. Available: http://www.ieee.org/

[6]. Google Places API http://code.google.com/apis/maps/documentation /places/

[7]. https://www.abrightclearweb.com/registering-adomain-name-with-GoDaddy-step-by-step

[8]. Location Based Services on Mobile in India For IAMAI - Version: 14 April 2008 http://www.iamai.in/Upload/policy/LBS_Draft_I ndicus.pdf

[9]. "Location Management for Mobile Devices", by Erik Wilde (School of Information, UC Berkeley) - February 2008.

[10].“Android Wireless Application Development", By Shane Condor and Lauren Darcy. 


\section{Cite this article as :}

Prof. Kalyani Pendke, Nishad Wankhede, Mayur Dhole, "Instant Searching System for Housing and Food in a City", International Journal of Scientific Research in Science, Engineering and Technology (IJSRSET), Online ISSN : 2394-4099, Print ISSN : 2395-1990, Volume 8 Issue 3, pp. 178-182, May-June 2021. Available

doi : https://doi.org/10.32628/IJSRSET2182101

Journal URL : https://ijsrset.com/IJSRSET2182101 